\title{
The Landscape of Mucopolysaccharidosis in Southern and Eastern European Countries: A Survey from 19 Specialistic Centers.
}

\section{Anna Tylki-Szymańska}

Memorial Hospital for Children

\section{Zsuzsanna Almássy}

Children's Hospital

\section{Violetta Christophidou Anastasiadou}

The Cyprus Institute of Neurology and Genetics

Daniela Avdjieva-Tzavella

Medical University of Sofia

Ingeborg Barisic

Children's Hospital Zagreb

\section{Rimante Cerkauskiene}

Vilnius University

\section{Goran Cuturilo}

University of Belgrade

\section{Maja Djiordjevic}

University of Belgrade

\section{Zoran Gucev}

University of Skopje Medical Faculty

\section{Anna Hlavata}

Comenius University in Bratislava Faculty of Medicine

\section{Beata Kieć-Wilk}

University Hospital in Krakow

\section{Martin Magner}

Charles University

\section{Ivan Pecin}

University of Zagreb School of Medicine

\section{Vasilica Plaiasu}

Carol Davila University of Medicine and Pharmacy Faculty of Pharmacy

\section{Mira Samardzic}

University of Montenegro

\section{Dimitrios Zafeiriou}


Aristotle University of Thessaloniki

\section{loannis Zaganas}

University of Crete Faculty of Medicine

Christina Lampe ( $\nabla$ christina.lampe@paediat.med.uni-giessen.de )

University of Giessen https://orcid.org/0000-0002-5529-0506

\section{Research}

Keywords: Mucopolysaccharidoses, Morquio A syndrome, Southern and Eastern European countries, enzyme replacement therapy, treatment accessibility.

Posted Date: November 19th, 2021

DOI: https://doi.org/10.21203/rs.3.rs-1071210/v1

License: (c) (i) This work is licensed under a Creative Commons Attribution 4.0 International License. Read Full License

Version of Record: A version of this preprint was published at Orphanet Journal of Rare Diseases on March 24th, 2022. See the published version at https://doi.org/10.1186/s13023-022-02285-x. 


\section{Abstract}

Background: Mucopolysaccharidoses (MPS) are a group of lysosomal storage disorders caused by defects in genes coding for different lysosomal enzymes which degrade glycosaminoglycans. Impaired lysosomal degradation causes cell dysfunction leading to progressive multiorgan involvement, disabling consequences and poor life expectancy. Enzyme replacement therapy (ERT) is now available for most MPS types, offering beneficial effects on disease progression and improving quality of life of patients. The landscape of MPS in Europe is not completely described and studies on availability of treatment show that ERT is not adequately implemented, particularly in Southern and Eastern Europe. In this study we performed a survey analysis in main specialist centers in Southern and Eastern European countries, to outline the landscape of disease management in the region and understand ERT implementation, with particular reference to MPS IVA.

Results: 19 experts from 14 Southern and Eastern European countries in total responded to the survey. Results outlined a picture of MPS management in the region, with a high number of MPS patients managed in the centers and a high level of care. MPS II was the most prevalent followed by MPS IVA, with a particular high number of adult patients. The study particularly focused on management and treatment of MPS IVA patients. Adherence to current European Guidelines for follow-up of MPS IVA patients is generally adequate, although some important assessments are reported as difficult due to the lack of MPS skilled specialists. Availability of ERT in Southern and Eastern European countries is generally in line with other European regions, even though regulatory, organizational and reimbursement constrains are demanding.

Conclusions: The landscape of MPS in Southern and Eastern European countries is generally comparable to that of other European regions on the epidemiology, treatment accessibility and follow up difficulties. However, issues limiting ERT availability and reimbursement should be simplified, to start treatment as early as possible and make it available for more patients. Besides, educational programs dedicated to specialists should be implemented, particularly for pediatricians, clinical geneticists, surgeons, anesthesiologists and neurologists.

\section{Background}

The mucopolysaccharidoses (MPS) are a group of progressive inherited metabolic disorders caused by defects in the lysosomal enzymes required for the degradation of glycosaminoglycans (GAG). GAGs include chondroitin sulfate (CS), dermatan sulfate (DS), heparan sulfate (HS), keratan sulfate (KS), and hyaluronan. As a result of impaired catabolism, GAGs accumulate in lysosomes, causing cell dysfunction that leads to multisystemic clinical manifestations. Depending on the lysosomal enzyme defect involved, catabolism of single or multiple GAGs may be blocked, leading to distinct phenotypes classified as different types of MPS. Eleven enzymatic defects are described, causing seven different MPS types, with several subtypes. The collective incidence of MPS types has been estimated to more than 1 in 25,000 live births [1]. As common for genetic diseases, each MPS disorder may manifest across a spectrum of 
phenotypes, from mild to severe [2]. In general, most patients affected by MPS are asymptomatic at birth and display normal development for a time period, followed by a progressive emergence of the disease phenotype, characterized by physical and sometimes also mental function decline [3]. All MPS disorders share similar clinical multisystemic manifestations, including dysostosis multiplex, short stature, coarse facial features, kyphoscoliosis and spinal degenerative changes, subluxations or stenosis with compression of nerves or the spinal cord, joint stiffness, cognitive dysfunction, hepatosplenomegaly and hernias. Hearing, vision, and cardiopulmonary functions are also affected. The skeletal disorder is the main burden for MPS patients, with frequent loss of ambulation, chronic inflammation and disabling pain in the joints. As a result, patients with MPS often have a low quality of life, a short life expectancy and require life-long treatment [4,5]. Distinct symptoms and signs characterize different MPS subtypes, contributing to diagnosis, but early and accurate diagnosis in the asymptomatic stage would be essential for better treatment results and outcomes. Urinary and blood tests to detect GAGs accumulation, enzyme assays and genetic tests are now available to diagnose MPS and determine the specific subtype [3]. Historically, treatment of mucopolysaccharidoses has been symptomatic, mainly employing physical rehabilitation and surgery to alleviate the burden of skeletal deterioration. The first etiological treatment for MPS was allogenic transplant of hematopoietic cells in MPS I patients in 1980 [6]. Today, hematopoietic stem cell transplantation (HSCT) is an established treatment for MPS I and the use in other MPS is being reevaluated. However, specific enzyme replacement therapies (ERT) are now available for five MPS types - MPS I, II, IVA, VI and VII - based on human recombinant enzymes to replace the defective lysosomal enzymatic function. ERT is effective in alleviating the somatic clinical manifestations of the various MPS, including reduction of respiratory dysfunction, hepatomegaly and joint stiffness, significantly improving quality of life for patients with MPS [5]. These novel treatments have led to increased life expectancy, necessitating management through transition from childhood to adulthood for more patients. As for all rare metabolic diseases, MPS patients receive adequate pediatric care, while a structured transition process for patients going through adolescence, and then adulthood, is not always implemented [7].

In Europe, the landscape of MPS epidemiology and management, including implementation of transition of care and ERT availability, is not completely defined, particularly for Southern and Eastern countries [4]. With this publication, we aim to describe the real life MPS management in Southern and Eastern European countries, with particular reference to MPS type IVA.

MPS IVA, also known as Morquio A syndrome, is caused by pathogenic variants in the gene encoding the enzyme N-acetylgalactosamine-6-sulfate sulfatase (GALNS). The enzyme encoded by the defective gene is dysfunctional, causing intracellular accumulation of chondroitin-6-sulfate (C6S) and keratan sulfate in several tissues, particularly in bone, cartilage and cornea [8]. The result is a systemic skeletal chondrodysplasia, the typical clinical manifestation of MPS IVA [9]. More than 180 pathogenic variants in the GALNS gene have been identified, accounting for the large variety of MPS IVA phenotypes observed [10]. Even though the musculoskeletal system is the most significantly involved, multiple clinical presentations are observed, thus MPS IVA patients may require multi-disciplinary approaches for diagnosis and management [11]. Also, as Morquio A is the MPS with the longest overall survival, it often 
requires transfer of care from pediatric to adult physicians, arising the issue of appropriate transition. Clinical manifestations vary from a 'classical' syndrome characterized by early-onset and rapid progression of severe systemic bone dysplasia, to a slowly progressive later-onset (mild) form, with less severe bone involvement. An intermediate form has also been described. The "classical" phenotype is largely prevalent, accounting for $68.4 \%$ of all individuals affected with MPS IVA in the International Morquio Registry, while only $9.8 \%$ were categorized as mild and $15.1 \%$ as intermediate [12]. The severity of symptoms is determined by the degree of skeletal and joints' involvement. The most typical manifestation in MPS IVA affected patients is short stature, accompanied by spinal cord compression, spinal instability and thoracolumbar kyphoscoliosis, genu valgum, joint hypermobility, hip subluxation and dysplasia [13]. Spinal cord compression is the leading cause of mortality for MPS IVA patients, with an average life expectancy of 20-30 years if left untreated [14]. For this reason, MPS IVA patients often require surgical interventions in the upper cervical spine, generally before the age of 10 years [12]. Surgery in the lower extremities is also performed in most patients, to manage coxa valga, genu valgum and other deformations, although orthopedic interventions generally fail to provide resolutive and long lasting benefits [15]. Involvement of other organ systems can also lead to significant morbidity, including respiratory compromise, obstructive sleep apnea, valvular heart disease, hearing impairment, micturition disorders, visual impairment from corneal clouding, dental abnormalities, and hepatomegaly $[4,16]$.

Traditionally, patients with MPS IVA have been managed exclusively by supportive measures, including symptom-based medical management, physical therapy, rehabilitation, and surgery, but management options expanded in recent years [11]. Enzyme replacement therapy for MPS IVA using recombinant human GALNS, or elosulfase alfa [17], was approved by FDA and EMA in 2014, for children and adults with Morquio A syndrome [18]. In clinical trials performed in children and adults with MPS IVA, intravenous elosulfase alfa ( $2 \mathrm{mg} / \mathrm{kg} /$ week) provided significant and sustained improvements in urinary levels of KS [19]. Elosulfase alfa was also shown to improve endurance scores in patients treated for 24 weeks, as measured by the 6 minutes' walk test (6MWT) [20]. Improvement in endurance were also confirmed in a long-term study, up to 4.9 years, both in children and adults [21]. The latter study also showed positive results on clinical and patient-reported outcomes, such as pulmonary function measures and activities of daily living (ADL). Overall, findings from these and other studies suggest that long-term elosulfase alpha ERT is well tolerated and associated with partial recovery of the functional status, improving Morquio A patients' ability to perform ADL [22]. As a result, the use of elosulfase alfa is recommended in the last European Guidelines for the management of MPS IVA [23].

Despite established clinical guidelines, as it often occurs for rare diseases, the small number of studies on MPS IVA patients is a main obstacle for clinicians on the way to standard clinical practice. Also, as for all inherited metabolic diseases, pediatric care is well-established, while the shift to adult care is not always effective. Therefore, in this publication we aim to outline MPS IVA management in Southern and Eastern European Countries and to highlight critical features in general management of the disease, with particular reference to ERT availability. 


\section{Methods}

The "Mucopolysaccharidosis Management Physician Survey" was conducted online - via the Survey Monkey platform (www.surveymonkey.com) - between March and June 2020. The questionnaire was developed by the scientific coordinator of the project based on particular expertise in management of MPS patients. 19 MPS Experts from 14 different Eastern and Southern European countries participated in the survey (Bulgaria, Croatia, Cyprus, Czech Republic, Greece, Hungary, Lithuania, Montenegro, Poland, Republic of North Macedonia, Romania, Serbia, Slovakia, Slovenia) (Fig. 1). In the second phase of the project, in May 2021, the experts met in a Virtual Working Group Meeting, together with the scientific coordinator, to analyze the results of the first Survey. 16 experts in the management of MPS patients from 13 Eastern and Southern European countries participated to the meeting (Bulgaria, Croatia, Cyprus, Czech Republic, Greece, Hungary, Lithuania, Montenegro, Poland, Republic of North Macedonia, Romania, Serbia, Slovakia). 4 experts who contributed to the first survey could not participate to the meeting because of organizational issues and retirement, and 1 expert from Poland only participated to the second survey. During the meeting, results were discussed and some issues for further investigation were identified. Thus, a series of questions were included in a second questionnaire to be sent to this group of experts to refine data obtained from the first survey. The second "Mucopolysaccharidosis Management Physician Survey" was sent to this group of experts with the same modality between May and June 2021.

The Surveys consisted of a series of mostly closed questions, logically grouped into the following areas:

1. Screening: country of practice of physicians and main specialty

2. Physician Characteristics and Clinical Practice: demographic characteristics of MPS patients in each respondent's clinical practice

3. Experience with MPS type IVA (MPS IVA, Morquio A syndrome)

4. Management and Treatment of MPS type IVA: local practice in overall management, treatment and outcome assessment of patients with MPS IVA.

\section{Results}

These results are based on retrospective data collected during two rounds of the "Mucopolysaccharidosis Management Physician Survey". Overall, 19 experts in the management of MPS from 14 Southern and Eastern European countries participated to the first surveys (Fig. 1) and 16 of them, from 13 countries, also responded to the second. Combined results from the first and the second survey are presented.

\section{Country of practice of physicians and main specialty}

19 physicians with expertise in MPS management from 19 reference centers distributed across 14 different European countries participated in the first survey -2 centers in Bulgaria, 2 in Croatia, 1 in 
Cyprus, 1 in Czech Republic, 2 in Greece, 1 Hungary, 1 Lithuania, 1 in Montenegro, 1 in Poland, 1 in the Republic of North Macedonia, 1 in Romania, 3 in Serbia, 1 in Slovakia and 1 in Slovenia.

Due to retirement of some physicians and other organizational issues, 2 centers from Serbia, 1 from Slovenia and 1 from Bulgaria did not participate to the second survey. One center from Poland that was not present during the first survey, participated to the second. Thus, data collected in the second round describe the real-life of MPS for 16 centers in 13 Eastern and Southern European countries - 1 center in Bulgaria, 2 in Croatia, 1 in Cyprus, 1 in Czech Republic, 2 in Greece, 1 Hungary, 1 Lithuania, 1 in Montenegro, 2 in Poland, 1 the Republic of North Macedonia, 1 in Romania, 1 in Serbia, 1 in Slovakia.

Overall, among 19 physicians responding in the first survey, 53\% were pediatrician or medical geneticists (Fig. 2).

In the second survey, the specialty of physicians was defined in more detail. Only $19 \%$ of physicians (3/16) taking care of MPS patients were adult metabolic specialists, while $44 \%(6 / 16)$ were pediatrician. $44 \%$ of physicians were geneticists, routinely treating both pediatric and adult patients. Only one center specialized exclusively in pediatric care, but they also follow up patients during adulthood. $50 \%$ of participants (8/16) answered that they normally take care of both pediatric and adult patients, while $19 \%$ confirmed to manage only adults and $31 \%$ only children.

Concerning the collaboration with an adult center to refer the patient after childhood, almost $38 \%$ of respondents (5/16) confirmed the collaboration, while 2 physicians $(12 \%)$ declared to have no collaboration with an adult center. Three experts commented that there is no official dedicated center for the management of adult patients with inherited metabolic disease in their countries, but there is a high level of collaboration between pediatricians and adult specialists. One expert, with a specialization in pediatric and genetics, affirmed that in his center MPS patients are managed by pediatricians throughout their life.

Overall, these data suggest the lack of a structured process of transition of care, with the majority of MPS patients remaining in the hands of pediatricians throughout transition and in adulthood. Only a minor percentage of specialists taking care of adult MPS patients are specialized physicians for adults.

Concerning the expertise of physicians, about $50 \%$ of physicians had practiced medicine post residency for more than 25 years, all of them in an academic setting.

\section{Patients with a confirmed diagnosis of MPS included in the study}

Almost all the centers (95\%) declared to have managed at least one patient potentially affected by MPS IVA. 
In the second survey, the 16 experts reported that they managed in total 195 patients with a confirmed diagnosis of MPS I, II, IVA, VI and VII. The most frequent MPS type was MPS II with 75/195 patients (38\%), followed by MPS IVA with 63 patients (32\%), MPS I with 32 patients $(16 \%)$ and MPS VI with 23 patients (12\%). Only 2 patients with MPS VII were reported from 2 centers (Fig. 3).

Among all patients with a confirmed diagnosis of MPS, $63 \%$ were pediatric patients $(123 / 195)$ and $37 \%$ adults (72/195).

MPS IVA was the most frequent MPS type in adult patients, with $40 \%$ of all adult patients (29/72), while the largest group of pediatric patients was the MPS II group, with the $49 \%$ of all MPS affected children (60/123). Patients with MPS I were 32 (16\%), 12 adults and 20 children, while patients with MPS VI were $23(12 \%), 14$ adults and 9 children. Only 2 patients with a confirmed diagnosis of MPS VII were reported by 2 centers, both adults (Table 1 ).

Table 1. Number of patients of different age groups and MPS types. In parentheses the number of centers managing these patients.

\begin{tabular}{|llllll|}
\hline & $\mathbf{0 - 5}$ years & $\mathbf{6 - 1 2}$ years & $\mathbf{1 3 - 1 8}$ years & $>\mathbf{1 8}$ years & Total \\
\hline MPS Type I & $9(4)$ & $6(3)$ & $5(3)$ & $12(7)$ & $\mathbf{3 2}$ \\
\hline MPS Type II & $14(6)$ & $31(8)$ & $15(5)$ & $15(7)$ & $\mathbf{7 5}$ \\
\hline MPS Type IVA & 0 & $17(8)$ & $17(7)$ & $29(7)$ & $\mathbf{6 3}$ \\
\hline MPS Type VI & 0 & $4(3)$ & $5(4)$ & $14(5)$ & $\mathbf{2 3}$ \\
\hline MPS Type VII & 0 & 0 & 0 & $2(2)$ & $\mathbf{2}$ \\
\hline Total & 23 & 58 & 42 & 72 & 195 \\
\hline
\end{tabular}

\section{Patients on enzyme replacement therapy in different age groups}

Participants were asked to report about the number of patients receiving ERT in their centers, specifying the type of MPS and the age group of patients (Table 2).

Table 2. Patients receiving ERT divided by MPS type and age group. In parentheses the number of centers managing the patients. 


\begin{tabular}{|llllll|}
\hline & $\mathbf{0 - 5}$ years & $\mathbf{6 - 1 2}$ years & $\mathbf{1 3 - 1 8}$ years & $>\mathbf{1 8}$ years & Total \\
\hline MPS Type I & $5(2)$ & $2(1)$ & $3(2)$ & $11(6)$ & $\mathbf{2 1}$ \\
\hline MPS Type II & $9(4)$ & $24(8)$ & $12(4)$ & $7(5)$ & $\mathbf{5 2}$ \\
\hline MPS Type IVA & 0 & $11(7)$ & $8(5)$ & $6(3)$ & $\mathbf{2 5}$ \\
\hline MPS Type VI & 0 & $3(2)$ & $3(3)$ & $8(5)$ & $\mathbf{1 4}$ \\
\hline MPS Type VII & 0 & 0 & 0 & 0 & 0 \\
\hline Total & $\mathbf{1 4}$ & $\mathbf{4 0}$ & $\mathbf{2 6}$ & 32 & $\mathbf{1 1 2}$ \\
\hline
\end{tabular}

In total, $57 \%$ of all MPS patients $(112 / 195)$ are on treatment with enzyme replacement therapy; among them $71 \%$ are pediatric patients (80/112) and $29 \%(32 / 112)$ are adults.

The age group 0-5 years included 23 patients in total and 14 of them (61\%) are receiving ERT. Among the age group, 9 children are MPS I patients from 4 centers (Table 1) and 5 of them are treated with ERT in 2 centers. We don't have data on HSCT for these patients, thus ERT could have not been administered in transplanted patients. Also, among 14 MPS II patients in 6 centers, 9 are receiving ERT in 4 centers. No MPS IVA, VI or MPS VII patients on ERT were reported in this age group.

The age group 6-12 years counted 58 patients and 40 of them (69\%) are treated with ERT. The most frequent MPS type is MPS II with 31 patients (53\% of the age group) from 8 centers and 24 of them (77\%) are treated with enzyme replacement therapy in 8 centers. There are 17 MPS IVA patients from 8 centers and 11 of them are receiving ERT in all centers (65\%). Only 4 MPS VI patients were reported from 3 centers and 3 of them are on ERT in 2 centers.

In the age group of 13-18 years, 42 MPS patients were reported in total, and 26 are treated with ERT (62\%). The most frequent MPS type is MPS IVA, with $40 \%$ (17/42) of all patients from 7 centers, among which $8(47 \%)$ are on ERT treatment in 5 centers. 15 patients in this age group are MPS II patients, from 5 centers, and 12 (80\%) of them are on ERT in 4 centers. 5 MPS VI patients were reported by 4 centers and 3 of them are on ERT treatment in 3 centers. 5 patients from 4 centers in the age group have MPS I and 3 of them are on ERT in 2 centers.

In the age group of adults ( $>18$ years), 72 patients were reported in total with a confirmed diagnosis of MPS and 32 of them (44\%) are receiving ERT. The MPS IVA group was the most numerous, with 29 patients in 7 centers ( $40 \%$ of the age group, Table 1), but only 6 of them were reported to be on ERT treatment ( $21 \%$ of total MPS IVA) (Table 2). 15 adult patients from 7 centers have MPS II ( $21 \%$ of the age group) and 7 are receiving ERT in 5 centers; 14 patients were reported from 5 centers in the MPS VI group (19\% of the age group) with 8 of them receiving ERT in 5 centers. Patients with MPS I represented the $17 \%$ of the age group, with 12 patients from 7 centers and 11 are treated with ERT in 6 centers. Only 2 patients with MPS VII were reported by 2 centers, not receiving ERT treatment. 
Overall, in patients of all ages, MPS II patients represent the majority of ERT treated individuals (46.5\% of all treated patients), followed by MPS IVA patients (22\%) and MPS I (19\%). Only $12.5 \%$ of treated patients have MPS VI and no patient in the MPS VII group is on treatment (Fig. 4).

In general, ERT is much more available for pediatric patients ( $65 \%$ of all affected children) than for adults (44\% of adult patients with all MPS types receive ERT).

\section{Availability of ERT in different countries}

Physicians were asked to report on the availability of ERT in their country, specifying the type of MPS treated patients (Table 3).

Table 3. Availability of ERT for MPS diseases in different countries. In brackets the \% of respondents.

\begin{tabular}{|c|c|c|c|c|c}
\multicolumn{2}{c}{$\begin{array}{c}\text { Not } \\
\text { available }\end{array}$} & $\begin{array}{c}\text { Available for } \\
\text { all ages }\end{array}$ & $\begin{array}{c}\text { Available only } \\
\text { for pediatric } \\
\text { patients }\end{array}$ & $\begin{array}{c}\text { Available only } \\
\text { for some } \\
\text { patients }\end{array}$ & Total \\
\hline MPS Type I & $2(14 \%)$ & $10(71 \%)$ & $1(7 \%)$ & $1(7 \%)$ & 14 \\
\hline MPS Type II & $0(0 \%)$ & $12(86 \%)$ & $1(7 \%)$ & $1(7 \%)$ & 14 \\
\hline MPS Type IVA & $2(12,5 \%)$ & $10(62,5 \%)$ & $2(12,5 \%)$ & $2(12,5 \%)$ & 16 \\
\hline MPS Type VI & $2(17 \%)$ & $9(75 \%)$ & $0(0 \%)$ & $1(8 \%)$ & 12 \\
\hline MPS Type VII & $9(75 \%)$ & $2(17) \%$ & $0(0 \%)$ & $1(8 \%)$ & 12 \\
\hline
\end{tabular}

For MPS I, ERT is available for all age groups in 10 out of 14 centers that answered the question (71\%). ERT is available only for pediatric patients with MPS I in 1 center and only for some patients in another center. 2 centers have no access to ERT for MPS I patients.

Concerning MPS II patients, all centers that responded (14/16) declared to have access to ERT. Overall, ERT is largely available for patients with MPS II of all ages, in 12 of 14 centers (86\%). ERT is available only for pediatric patients with MPS II in 1 center and only for some patients in another center.

All centers answered about availability of ERT for MPS IVA. ERT is available for patients of all ages in 10 centers $(62.5 \%)$, while 2 centers are able only to treat pediatric patients and in other 2 centers ERT it is available only for some patients. 2 centers have no access to ERT for MPS IVA patients.

For MPS VI patients ERT is available for all ages in $9 / 12$ centers $(75 \%)$ and in 1 center only for some patients. In 2 centers it is not available.

Finally, 12 centers responded about ERT for MPS VII patients, affirming that it is available in only 2 centers for all ages (25\%), and in 1 center only for some patients. 9 centers have no access to ERT for MPS VII patients. 


\section{Difficulties in treating MPS IVA patients with ERT}

In the first survey, $84 \%$ of experts from 19 centers declared that ERT is available in their countries. In $69 \%$ of centers reimbursement is by individual patient request to the National Health Insurance Fund and in $31 \%$ by positive list, meaning national reimbursement.

However, in the second survey, $75 \%$ of centers declared that it is a difficult and long process to get reimbursement for ERT. $18 \%$ of centers invoked organizational problems in performing follow up examinations and $12 \%$ organizational problems in performing ERT (Table 4).

Table 4. Reasons for difficulties in treating MPS IV patients. In brackets the percentage of responders.

\begin{tabular}{|ll|}
\hline Answer Choices & Responses \\
\hline Difficult and long administrative process to get reimbursement & $12(75 \%)$ \\
\hline Patients do not want to be treated & $1(6 \%)$ \\
\hline Organization problems in performing ERT & $2(12 \%)$ \\
\hline Organization problems in performing follow up examinations & $3(18 \%)$ \\
\hline Others & $4(25 \%)$ \\
\hline
\end{tabular}

Some participants mentioned other reasons for difficulties in treating patients with ERT. For instance, one expert stated that ERT reimbursement is difficult because of frequent reports to the health insurance company about the effectiveness of treatment (every 6-12 months), for having allowance to continue treatment. Another participant declared that ERT for MPS IVA is available in the country but not reimbursed.

Moreover, the average hours to perform application for reimbursement varies from 2 hours to several days (not including the time to get a response from the healthcare authorities), considerably limiting ERT implementation.

\section{Defining the group of MPS IVA patients}

MPS IVA patients represent $32 \%$ of all MPS patients (63/195) included in the study (Table 1). 29 are adult patients (46\%) and 34 are pediatric patients (54\%). There are no MPS IVA patients in the age group 0-5 years. 17 patients are in the age group 6-12 years, 11 of which are receiving ERT, and 17 in the age group 13-18 years, of which 8 are on ERT treatment (Table 1 and 2). Overall, $40 \%(25 / 63)$ of MPS IVA patients of all ages are on ERT treatment in the 16 centers involved in the study. 6 sibling pairs are included in the group. 
Among patients with MPS IVA who are on ERT treatment, only 4 were reported to be wheelchair bound, 2 in the age group 13-18 years and 2 in the adult group (Table 5).

Table 5. Wheelchair bound and ambulatory patients with MPS IVA on ERT treatment.

\begin{tabular}{|llllll|}
\hline & $0-5$ years & $6-12$ years & $13-18$ years & $>18$ years & Total \\
\hline Wheelchair bound & 0 & 0 & 2 & 2 & 4 \\
\hline Ambulatory & 0 & 10 & 6 & 4 & 20 \\
\hline Total & 0 & 10 & 8 & 6 & 24 \\
\hline
\end{tabular}

Almost all patients are defined as classical phenotypes, except 1 patient on ERT in the age group 13-18 years and 1 adult patient who is not treated.

Moreover, to better understand the prevalence of MPS IVA in the countries represented, experts were also asked if they knew other centers in the country taking care of MPS IVA patients. 6 experts declared to be aware of some other centers in their country, but the estimated number of patients was uncertain (between 1 and 10).

\section{Availability of assessments and difficulties in following the guidelines for MPS IVA completely}

Participants were asked to self-evaluate the respondence of assessments performed in their centers on MPS IVA patients with the European Guidelines for management of MPS IVA patients [23].

Although 16 experts (89\%) in the first survey declared to follow the European Guidelines, in the second survey several difficulties in performing some of the assessments recommended emerged.

Participants were asked to define the availability of assessments for MPS IVA in their countries and how difficult is to perform them (Table 6).

Table 6. Self-evaluation of difficulties in following the assessments recommended by the European Guidelines for monitoring MPS IVA patients. \% of respondents. 6MWT: 6 minutes walk test; CT scan: computerized tomography scan; ECG: electrocardiogram; echo: echocardiogram; EQ-5D-5L: 5-level EuroQoL -5D questionnaire; FVC: Forced Vital Capacity; JROM: Joint Range of Motion; MPS-HAQ; MPS health assessment questionnaire; MRI: Magnetic Resonance Imaging; MVV: Maximum voluntary ventilation; PRO; patient reported outcomes. 


\begin{tabular}{|c|c|c|c|c|c|c|}
\hline & $\begin{array}{l}\text { very } \\
\text { easy }\end{array}$ & easy & $\begin{array}{l}\text { somehow } \\
\text { difficult }\end{array}$ & difficult & $\begin{array}{l}\text { very } \\
\text { difficult }\end{array}$ & Total \\
\hline General Physical examination & $50 \%$ & $31 \%$ & $19 \%$ & $0 \%$ & $0 \%$ & $\begin{array}{l}16 \\
(100 \%)\end{array}$ \\
\hline Neurological examination & $37 \%$ & $44 \%$ & $19 \%$ & $0 \%$ & $0 \%$ & $\begin{array}{l}16 \\
(100 \%)\end{array}$ \\
\hline Joint range of motion (JROM) & $25 \%$ & $50 \%$ & $19 \%$ & $6 \%$ & $0 \%$ & $\begin{array}{l}16 \\
(100 \%)\end{array}$ \\
\hline Growth & $62 \%$ & $25 \%$ & $13 \%$ & $0 \%$ & $0 \%$ & $\begin{array}{l}16 \\
(100 \%)\end{array}$ \\
\hline Endurance (6MWT) & $50 \%$ & $25 \%$ & $25 \%$ & $0 \%$ & $0 \%$ & $\begin{array}{l}16 \\
(100 \%)\end{array}$ \\
\hline X-rays & $56 \%$ & $31 \%$ & $13 \%$ & $0 \%$ & $0 \%$ & $\begin{array}{l}16 \\
(100 \%)\end{array}$ \\
\hline MRI & $25 \%$ & $44 \%$ & $19 \%$ & $12 \%$ & $0 \%$ & $\begin{array}{l}16 \\
(100 \%)\end{array}$ \\
\hline CT scan & $31 \%$ & $44 \%$ & $19 \%$ & $6 \%$ & $0 \%$ & $\begin{array}{l}16 \\
(100 \%)\end{array}$ \\
\hline Cardiology (echo, ecg) & $44 \%$ & $44 \%$ & $6 \%$ & $6 \%$ & $0 \%$ & $\begin{array}{l}16 \\
(100 \%)\end{array}$ \\
\hline Respiratory function (MVV, FVC) & $31 \%$ & $38 \%$ & $31 \%$ & $0 \%$ & $0 \%$ & $\begin{array}{l}16 \\
(100 \%)\end{array}$ \\
\hline Sleep study & $0 \%$ & $31 \%$ & $50 \%$ & $6 \%$ & $13 \%$ & $\begin{array}{l}16 \\
(100 \%)\end{array}$ \\
\hline Oral health & $31 \%$ & $31 \%$ & $38 \%$ & $0 \%$ & $0 \%$ & $\begin{array}{l}16 \\
(100 \%)\end{array}$ \\
\hline Eye examination & $37.5 \%$ & $37.5 \%$ & $25 \%$ & $0 \%$ & $0 \%$ & $\begin{array}{l}16 \\
(100 \%)\end{array}$ \\
\hline Ear examination & $37 \%$ & $44 \%$ & $19 \%$ & $0 \%$ & $0 \%$ & $\begin{array}{l}16 \\
(100 \%)\end{array}$ \\
\hline $\begin{array}{l}\text { Disease burden (EQ-5D-5L, MPS } \\
\text { HAQ, PRO) }\end{array}$ & $19 \%$ & $50 \%$ & $25 \%$ & $6 \%$ & $0 \%$ & $\begin{array}{l}16 \\
(100 \%)\end{array}$ \\
\hline Anesthesia & $25 \%$ & $31 \%$ & $25 \%$ & $13 \%$ & $6 \%$ & $\begin{array}{l}16 \\
(100 \%)\end{array}$ \\
\hline Surgical interventions & $13 \%$ & $31 \%$ & $37 \%$ & $13 \%$ & $6 \%$ & $\begin{array}{l}16 \\
(100 \%)\end{array}$ \\
\hline electrophysiology & $19 \%$ & $38 \%$ & $31 \%$ & $6 \%$ & $6 \%$ & $\begin{array}{l}16 \\
(100 \%)\end{array}$ \\
\hline Lab testing & $32 \%$ & $56 \%$ & $6 \%$ & $6 \%$ & $0 \%$ & 16 \\
\hline
\end{tabular}


Most experts (87-88\%) affirmed that growth, cardiological examination, laboratory testing, and X-ray are "easy" or "very easy" assessments in their centers. Likewise, $81 \%$ of all experts $(13 / 16)$ defined general physical examination, neurological examination and ear examination as "easy" or "very easy".

Joint range of motion (JROM), endurance (6MWT), computerized tomography (CT) scan and eye examination were scored as "easy" or "very easy" by $75 \%$ of participants $(12 / 16)$.

Respiratory function was defined as "easy or very easy" in $69 \%$ of centers (11/16), while 5 centers (31\%) answered they have some difficulties in performing the assessment. Magnetic resonance imaging (MRI) examination is also "easy or very easy" for $69 \%$ of respondents (11/16), "somehow difficult" in $19 \%$ $(3 / 16)$ and "difficult or very difficult" in $12 \%(2 / 16)$ centers.

Oral health is "easy or very easy" in $62 \%(10 / 16)$ of centers, and "somehow difficult" in $37 \%(6 / 16)$.

Anesthesia seems to be "easy" or "very easy" in $56 \%$ of centers (9/16) and "difficult" or "very difficult" in 3 centers.

Surgical intervention was defined "easy" or "very easy" in only $44 \%(7 / 16)$ of centers, while $37 \%(6 / 16)$ defined it "somehow difficult" and 19\% (3/16) "difficult or very difficult".

Sleep studies are defined as "easy" in $31 \%$ of the centers (5/16). No center declared that sleep studies are "very easy". $50 \%$ of the centers $(8 / 16)$ stated that they have some difficulties in performing the assessment, and 3 centers (19\%) defined sleep studies as "difficult" or "very difficult" to perform.

Electrophysiology was mostly defined as "easy or very easy" in $56 \%$ of centers (9/16), "somehow difficult" in $31 \%(5 / 16)$ and "difficult" or "very difficult" in 2 centers.

In summary, 3 centers (19\%) asserted to have real difficulties in performing some assessments for MPS IVA patients, namely sleep studies, anesthesia, and surgical interventions. Also, 2 centers have difficulties in performing electrophysiology studies and 2 with MRI. Disease burden indexes, lab testing, JROM, CT scan and cardiological examinations were all defined as "difficult" or "very difficult" in 1 center.

Participants were also asked to define the main issues for not following the guidelines completely. The main questions cited were organizational and administrative ( $81 \%$ and $62 \%$ respectively) and only $19 \%$ of respondents claimed financial problems.

\section{Methods to confirm diagnosis of MPS IVA before starting treatment}

In the second survey, the experts were asked to define the methods currently used to confirm diagnosis of MPS IVA before initiating ERT treatment (Fig. 5). 
The most cited methods were urinary keratan sulfate and dry blood spot test for enzyme assay (63\% of experts, 10/16), followed by genetic testing and dry blood test for genetics, that were considered appropriated by $50 \%$ of respondents. 7 experts (44\%) mentioned enzyme activity test (in blood or fibroblasts) and 2 declared to use other methods.

\section{Routinely performed tests in MPS IVA patients}

In the first survey participants were asked to describe the clinical practice for routine monitoring of MPS IVA patients, with reference to assessments before initiating ERT and for monitoring response to treatment.

Most experts (84\%) declared to routinely perform endurance test (6MWT) before initiating ERT. Endurance testing is then carried out in most cases (84\%) every 6-12 months. There is no complete agreement on the most appropriate interval for monitoring ERT response using 6MWT. A slight majority of experts (53\%) fixes the interval at 6 months, $32 \%$ at one year, $10 \%$ at 3 months and $5 \%$ at 18 months

Respiratory function is also routinely performed before initiating treatment by $89 \%$ of experts $(17 / 19)$. More than $50 \%$ of experts perform respiratory function at least annually, $37 \%$ every 6 months, while $10 \%$ of experts never perform the test.

The parameter of respiratory function considered most appropriate to demonstrate the clinical benefit of ERT is Forced Vital Capacity (FVC), for $68 \%$ of experts, followed by Maximum Voluntary Ventilation measurement (MVV) (42\%), while $32 \%$ of respondents believe that all parameters indicated in the question are appropriate (Fig. 6).

Cardiac function assessments were defined appropriate measures to prove clinical benefit of ERT by $68 \%$ of experts (13/19). Among cardiac function parameters, ultrasound was considered the most appropriate measure by $75 \%$ of experts, and the 12 -lead electrocardiogram by $58 \%$ of respondents. Also, $50 \%$ of experts agreed that vital sign measurement are appropriate outcomes to evaluate effectivity of ERT (Fig. 7).

\section{Evaluation of important outcomes for monitoring response to ERT in MPS IVA patients.}

In the first survey, $89 \%$ of experts (17/19) declared to follow the recommendations in the last published European guidelines [23] for monitoring the effectiveness of enzyme replacement therapy in MPS IVA patients. However, only $32 \%$ of experts affirmed to have a clear definition for "satisfactory or nonsatisfactory" response to ERT, and most of them (58\%) answered they could not give a definitive response. 
Thus, to better understand the real life clinical practice for ERT evaluation at a regional level, in the second survey participants were asked to estimate the importance of assessments for monitoring the effectiveness of ERT in MPS IVA patients recommended in the European Guidelines, scoring them as "not important", "somehow important", "important" or "very important".

Table 7 Self-evaluation of the importance of assessments recommended in the European Guidelines for monitoring the effectiveness of ERT in MPS IVA patients. \% of respondents. 6MWT: 6 minutes walk test; CT scan: computerized tomography scan; ECG: electrocardiogram; echo: echocardiogram; EQ-5D-5L: 5level EuroQoL -5D questionnaire; FVC: Forced Vital Capacity; JROM: Joint Range of Motion; MPS-HAQ; MPS health assessment questionnaire; MRI: Magnetic Resonance Imaging; MVV: Maximum voluntary ventilation; PRO; patient reported outcomes.

\begin{tabular}{|c|c|c|c|c|c|}
\hline & $\begin{array}{c}\text { very } \\
\text { important }\end{array}$ & important & $\begin{array}{l}\text { somehow } \\
\text { important }\end{array}$ & $\begin{array}{c}\text { not } \\
\text { important }\end{array}$ & Total \\
\hline General Physical examination & $88 \%$ & $12 \%$ & $0 \%$ & $0 \%$ & $16(100 \%)$ \\
\hline Neurological examination & $44 \%$ & $37 \%$ & $19 \%$ & $0 \%$ & $16(100 \%)$ \\
\hline Joint range of motion (JROM) & $44 \%$ & $50 \%$ & $0 \%$ & $6 \%$ & $16(100 \%)$ \\
\hline Growth & $44 \%$ & $50 \%$ & $6 \%$ & $0 \%$ & $16(100 \%)$ \\
\hline Endurance (6MWT) & $56 \%$ & $31 \%$ & $13 \%$ & $0 \%$ & $16(100 \%)$ \\
\hline X-rays & $19 \%$ & $69 \%$ & $12 \%$ & $0 \%$ & $16(100 \%)$ \\
\hline MRI & $44 \%$ & $31 \%$ & $19 \%$ & $6 \%$ & $16(100 \%)$ \\
\hline CT scan & $25 \%$ & $38 \%$ & $31 \%$ & $6 \%$ & $16(100 \%)$ \\
\hline Cardiology (echo, ecg) & $31 \%$ & $69 \%$ & $0 \%$ & $0 \%$ & $16(100 \%)$ \\
\hline Respiratory function (MVV, FVC) & $56 \%$ & $44 \%$ & $0 \%$ & $0 \%$ & $16(100 \%)$ \\
\hline Sleep study & $13 \%$ & $56 \%$ & $31 \%$ & $0 \%$ & $16(100 \%)$ \\
\hline Oral health & $6 \%$ & $50 \%$ & $44 \%$ & $0 \%$ & $16(100 \%)$ \\
\hline Disease burden (EQ-5D-5L, MPS HAQ PRO) & $31 \%$ & $56 \%$ & $13 \%$ & $0 \%$ & $16(100 \%)$ \\
\hline Anesthesia & $44 \%$ & $37 \%$ & $13 \%$ & $6 \%$ & $16(100 \%)$ \\
\hline Surgical interventions & $44 \%$ & $37 \%$ & $13 \%$ & $6 \%$ & $16(100 \%)$ \\
\hline Electrophysiology & $19 \%$ & $62 \%$ & $6 \%$ & $13 \%$ & $16(100 \%)$ \\
\hline
\end{tabular}

General physical examination, respiratory function and cardiology assessments were defined as "important" or "very important" for monitoring the effectiveness of ERT by all experts (Table 7). Also, almost all participants $(15 / 16,94 \%)$ scored JROM and growth assessment as "very important or Important". Endurance test (6MWT), X-ray examination and disease burden indexes were considered "important" or "very important" by $87 \%$ of experts $(14 / 16)$, while neurological examination, surgical interventions, anesthesia and electrophysiology by 13 participants (81\%). Sleep study was rated as "important or very important" by $69 \%$ of respondents (11/16) and CT scan by 10 experts $(62 \%)$, while 5 experts affirmed it is only "somehow important". Concerning oral health, only $56 \%$ of experts $(9 / 16)$ consider it "important or very important" and $44 \%$ only "somehow important".

\section{Discussion}


This survey investigated the real life MPS management in Southern and Eastern European countries. MPSs are very rare inherited disorders, characterized by early clinical symptoms, progressive course and involvement of virtually all organs and systems. Due to severe and progressive symptoms, patients with MPS experience a low quality of life and require continuous help from other people all along their life. Generally, diagnosis is delayed until the appearance of first symptoms; however, considering the progressive nature of MPS disorders, treatment should be initiated as soon as possible after diagnosis, possibly even before evident clinical features are visible. [24]. Considering these issues, this study aims to describe the landscape of disease management in Southern and Eastern Europe and to outline eventual gaps in diagnosis, follow-up, transition and treatment of patients with MPS. ERT is currently the most appropriate and effective treatment for lysosomal enzymatic disorders. Beyond the specificity of effects in different MPS types, generally ERT aims to reduce GAG accumulation, thus delaying progression of disease and ameliorating quality of life [25]. First introduced in 1991 for the treatment of Gaucher disease [26], in the last 20 years ERT has become available for other lysosomal storage disorders, including some types of MPS. Laronidase was the first ERT for MPS, approved for the treatment of MPS I (Hurler, HurlerScheie, Scheie syndrome) in 2003 [27]; subsequently the treatment with galsufase became available for MPS VI (Maroteaux-Lamy syndrome), approved by the European Medicines Agency (EMA) in January 2006 [28]. ERT with idursulfase for MPS II (Hunter syndrome) is available in Europe since January 2007 [29] and elosulfase alfa for MPS IVA (Morquio A syndrome) was approved by the FDA and EMA in 2014 [18]. More recently, in August 2018, ERT with vestronidase alfa also became available for the treatment of MPS VII (Sly syndrome) [30] [for review on ERT see reference 31]. Indications vary across different MPS, but generally ERT is used in patients with moderate to severe disease or complications, although data indicate that treatment is much more effective if started very early (preferably in the pre-symptomatic phase) $[24,25]$. However, ERT is not effective in the neuropathic forms of MPS, given the inability of recombinant enzymes to cross the blood-brain barrier. Also, implementation of ERT varies across different countries, due to hurdles in national regulatory or reimbursement procedures [32]. To understand access to treatment with ERT for MPS, the difficulties of reimbursement, as well as the accessibility to follow-up examinations and assessments recommended in the relevant practice guidelines, we performed a survey analysis among physicians specialized in the treatment of patients with MPS in 14 Southern and Eastern European countries. The survey was distributed using SurveyMonkey, an online platform allowing easy accessibility to the questions for the physicians and fast collection of responses. The first SurveyMonkey included a series of general questions to understand fundamental aspects of MPS management in the region. Results revealed an interesting context of disease management, with a high number of MPS patients managed in the centers and a high level of care, despite regulatory and administrative hurdles. Thus, after discussing with all participants the results of this first survey, a second survey was performed, to better describe some critical aspects that have emerged, mainly concerning the age of patients with MPS included in the study and the availability of treatment and follow-up examinations. Due to the increasing availability of diagnostic methods and advances in medical and surgical treatment options in recent years, a higher number of patients are diagnosed at an earlier age, life expectancy has increased, and more patients reach adulthood. In this setting, the issue of transition of MPS patients from pediatric to adult care is particularly of concern [7]. The management of transition 
in patients with inherited metabolic disorders (IMD) has been recently investigated in a large multicenter European survey performed by the European Reference Network for Hereditary Metabolic Disorders (MetabERN) [33]. Although the MetabERN survey was referred to the management of all IMDs and not focused on MPS, $87.1 \%$ of respondents were physicians specialized in the management of lysosomal storage disorders. Comparing our data with those of the MetabERN survey, our study revealed a significantly higher number of adult specialists taking care of MPS patients, a smaller percentage of pediatricians and a largely greater proportion of clinical geneticists (Table 8).

Table 8

Specialization of physicians taking care of MPS patients (our survey) compared to results of the MetabERN survey on management of IMD in Europe [33].

\begin{tabular}{|lll|}
\hline & Our Survey & MetabERN Survey on IMD \\
\hline Adult Physicians & $19 \%$ & $11.1 \%$ \\
\hline Pediatricians & $44 \%$ & $65.1 \%$ \\
\hline Clinical geneticists & $44 \%$ & $4.8 \%$ \\
\hline Physicians treating only adults & $19 \%$ & $6.4 \%$ \\
\hline Physicians treating both children and adults & $50 \%$ & $84.2 \%$ \\
\hline Collaboration with adult centers & $38 \%$ & $30.7 \%$ \\
\hline
\end{tabular}

This is particularly relevant if we consider that $37 \%$ of MPS patients included in our study were adults, an unexpectedly high number. Although it was not possible to find a comparison in the literature, numbers are certainly relevant and indicate the optimal management of patients with MPS in the centers, particularly considering the attention dedicated to adult patients. Also, despite regulatory difficulties in treating adult patients in many countries, almost half of adult patients in our study are receiving ERT ( $44 \%$ of total adults and $29 \%$ of all patients treated). These data outline a positive situation for MPS management in Southern and Eastern European countries included in the study. As it also has emerged during discussion within the group of experts, positive results are probably due to the high rate of physician engagement, in terms of willingness and personal involvement to provide the highest level of care for patients, in spite of hurdles in the healthcare system.

Describing the relative frequency of MPS types in the centers involved in our study, some peculiarities deserve consideration. Epidemiology of different types of MPS indicates that it may be related to regional and ethnic background. In Europe, MPS I, III and II are respectively the most prevalent, followed by MPS IV [4]. Similarly, MPS III is the most frequent in the US, MPS I and II come shortly after, while MPS IV is significantly less prevalent [34]. In our study, the most frequent MPS type was MPS II (39\%), closely followed by MPS IVA (33\%). MPS IVA affected individuals also represented the large majority of adult patients. No MPS III patients were included in our study because we focused on treaTable MPS forms. A similar high incidence of MPS II was only described in Sweden by Malm and coll. [35], while comparable data for MPS IVA were found in Norway and Denmark in the same study. The higher frequency of MPS II 
and the high number of MPS IVA patients in our study could be probably explained by the higher knowledge of physicians of these types of disease, leading to higher diagnosis. The high number of MPS IVA adult patients in Southern and Eastern Europe could be similarly explained by the high awareness of disease management among physicians and the high level of care, leading to more frequent screening for the disease. We have no explanation for our data based on region or ethnic group specific MPS types, nevertheless MPS IVA prevalence in our study is particularly significant and needs to be further investigated.

Concerning the accessibility to ERT treatment for MPS patients, according to our survey ERT is largely available for patients of all ages for MPS I, II, IV and VI, while it is still not available for MPS VII patients in most countries. However, this is not surprising, considering the extreme rarity of MPS VII. Interestingly, no MPS IVA, VI and VII patients under the age of 5 years are on treatment in all centers, suggesting the need for earlier diagnosis to initiate treatment as soon as possible. Unfortunately, ERT is available in all centers only for MPS II patients, which are also more frequently treated compared to patients with other MPS. Moreover, reimbursement for ERT is not accessible in all countries or the hurdles to overcome administrative issues are demanding. Mostly, the process to get reimbursement is complicated, excessively time-consuming and in some countries, it is necessary to apply for reimbursement for each patient, thus time from prescription to treatment is often long. Also, some experts claimed a pressing process to have renewal of reimbursement based on effectiveness for each patient or declared difficulties in performing follow-up examinations to assess effectiveness. It seems that availability of ERT and reimbursement is a particular concern in the three non-EU countries involved in our study, where treatment is mostly available only for patients with MPS II and IVA and preferably for pediatric patients. Accordingly, numbers of patients on treatment from these countries are small if compared to those in EU countries analyzed in the survey, probably because of additional economical, regulatory or organizational barriers outside the EU.

Overall, our results are consistent with the survey performed by Heard in 2020 [32], describing the availability of orphan medicines in 18 European countries in the MetabERN Network, including ERT for MPS I, II, IVA and VI. Among 25 orphan medicines analyzed in the study only 5 are available for the whole patient population, 12 are delivered to one-half and 8 products are rarely delivered to patients. Among the products prescribed to almost all patients when accessible, are idursulfase for MPS II and galsulfase for MPS VI. The restricted accessibility to treatment and the lack of reimbursement in several countries is a main finding of the study. Also, price negotiation for drugs do not take place at the European level, but at the member state level, probably causing particular budget constraints in some countries [36]. Comparing our data on ERT delivery with the availability of orphan medicines in the MetabERN network [32], it seems that availability of treatment in South and Eastern European countries is consistent with average data in other European regions. Also, the percentage of MPS treated patients in our centers is remarkable, particularly if we refer to almost one-half of MPS adult patients receiving ERT in our study. Still, in spite of regulatory, organizational and economical barriers, patients with MPS in Southern and Eastern European countries are receiving high level treatment. However, any effort should be addressed to reduce hurdles to accessibility to treatment.

Page 19/31 
The availability of follow-up assessments has been particularly investigated in MPS IVA patients from the 16 specialized centers responding to the second survey. Among the assessments recommended in the European guidelines for MPS IVA patients [23], it seems that surgery, anesthesiology and sleep studies are difficult in many centers. Reasons indicated for difficulties were mostly organizational problems in performing the assessments, administrative issue and financial problems in some centers. Also, experts reported the limited expertise about MPS and the inadequate number of qualified physicians and scientists with particular experience in management of MPS patients - in particular surgeons, anesthesiologists and neurologists with specific experience who are able to meet the traditional needs of MPS patients. Difficulties in collaborating with other specialists and the lack of a structured cooperation between specialists for a multidisciplinary management of patients was also claimed by some experts. This is not different from the situation of MPS management described in most other countries and the inadequate availability of specialist experts in MPS has also been claimed in other studies [37-39]. Nevertheless, the matter is particularly relevant and needs to be addressed. The implementation of training for physicians and other HCPs involved in care of MPS patients is a main necessity, as well as increasing the awareness about disease, spreading the knowledge about guidelines and best practice and facilitate multidisciplinary collaboration.

\section{Limitations}

The study has limitations which require consideration. This is a retrospective survey study of current practice for MPS management in 14 Southern and Eastern European countries, thus actual practice may vary from that reported. In addition, although main centers for disease management were included in the study, it does not capture all practice across the region, potentially introducing selection bias. Also, the study doesn't include data on HSCT for MPS patients, particularly for MPS I, which could partially explain the lack of ERT for some patients. Despite these limitations, the survey describes the real life of MPS in the region for the first time and provides a valuable insight into current practice.

\section{Conclusions}

The survey outlined the real life MPS management in Southern and Eastern European countries. The landscape of MPS in the region reveals a comparable picture to that of other European countries, as for the epidemiology of MPS types, treatment accessibility and follow-up difficulties. Still, in order to be able to start treatment as early as possible and make it available to more patients, diagnostic algorithms should be established and reimbursement for ERT should be simplified. In addition, this survey showed the need of further improving overall disease management and enhancing multidisciplinary collaboration among specialists, including through dedicated educational programs for specialists, on surgical interventions, anesthesia and sleep studies.

\section{Abbreviations}


6MWT: 6 minutes walk test; ADL: Activities of daily living; C6S: Chondroitin-6-sulfate; CT scan: Computerized tomography scan; DBS: Dried blood spot; ECG: Electrocardiogram; echo: Echocardiogram; EMA: European Medicines Agency; EQ-5D-5L: 5-level EuroQoL -5-dimensions questionnaire; ERT: Enzyme replacement therapy; FVC: Forced vital capacity; GAG: glycosaminoglycans; GALNS: Nacetylgalactosamine-6-sulfate sulfatase; HSCT: Hematopoietic stem cell transplantation; IMD: Inherited metabolic disorder; JROM: Joint Range of Motion; KS: Keratan sulphate; LSD: Lysosomal storage disorder; MPS: Mucopolysaccharidoses; MPS-HAQ: MPS health assessment questionnaire; MRI: Magnetic resonance imaging; MVV: Maximum voluntary ventilation; PRO: Patient reported outcomes.

\section{Declarations}

\section{Acknowledgements}

We gratefully acknowledge Prof. Adrijan Saraijlia (Mother and Child Health Care Institute of Serbia, Belgrade), Prof. Mojca Zerjav Tansek (University Children's Hospital, Ljubljana, Slovenia) and Prof. Radka Tincheva (University Pediatric Hospital Sofia, Bulgaria) who provided insight and expertise that greatly assisted the research during the first survey, although they could not share all the phasis of the project due to retirement and other administrative reasons. The Expert Board meetings and SurveyMonkey processing were supported by CD Pharma Group, an Italian independent consulting company, with the financial support of BioMarin Pharmaceutical Inc. We wish to thank Dr. Chiara Cappellini, who provided medical writing assistance with the financial support of CD Pharma Group.

\section{Funding}

This work was supported by BioMarin Pharmaceuticals Inc.

\section{Competing interests}

Z. Almassyzs, V. Anastasiadou, I. Barisic, R. Čerkauskienė, M Djordjevic, A. Hlavata, B. Kiec-Wilk, V. Plaiasu, M. Samardzic have no competing interests to declare.

D. Avdjieva-Tzavella has received speaker honoraria, travel and accommodation funding from Takeda and Sanofi Genzyme.

G. Cuturilo has received speaker honoraria and/or travel grants from BioMarin, Takeda and Sanofi Genzyme.

Z. Gucev has received speaker and advisory board honoraria from Novo Nordisk, Merck, and Takeda.

C. Lampe has received advisory board and speaker honoraria, travel expenses and consultancy honoraria from Sanofi, BioMarin, Amicus, Alexion, Takeda, Chiesi, Regenxbio.

M. Magner has received speaker honoraria from BioMarin and Takeda and consultancy fees from BioMarin and Chiesi. 
I. Pecin has received advisory board and speaker honoraria from Sanofi, Sandoz, Genzyme, Takeda, Amicus.

A. Tylki-Sziymanska has received speaker honoraria and/or travel grants from BioMarin, Sanofi Genzyme, Alexion, Chiesi, and Shire/Takeda.

D. Zafeiriou has received honoraria, travel and research grants from Sanofi-Genzyme, Takeda, BioMarin, Novartis, Biogen and UCB.

I. Zaganas has received consultancy honoraria from Akcea, Alnylam, BioMarin, Genesis Pharma, Roche, Specifar/Teva.

\section{Authors' contributions}

All authors were members of the expert board and actively participated to the survey and discussion of data. C. Lampe was the scientific coordinator of the project. Dr. Lampe directed and supervised all the phases of the study, specifically contributing to the development of the survey, analysis and discussion of results and writing of the manuscript. A. Tylki-Sziymanska gave a particularly helpful contribution to the discussion of results and revised the article. All authors read and approved the submitted manuscript.

\section{Availability of data and materials}

All data generated or analysed during this study are included in this published article.

\section{Ethics approval and consent to participate}

Not applicable.

\section{Consent for publication}

Not applicable.

\section{References}

1. Muenzer J. Overview of the mucopolysaccharidoses. Rheumatology (Oxford). 2011;50 Suppl 5:v412.

2. Neufeld EF, Muenzer J: The mucopolysaccharidoses. In: Valle DL, Antonarakis S, Ballabio A, Beaudet AL, Mitchell GA (eds): The Online Metabolic and Molecular Bases of Inherited Disease, New York, NY: McGraw-Hill Education, 2019.

3. Tomatsu S, Fujii T, Fukushi M, Oguma T, Shimada T, Maeda M, et al. Newborn screening and diagnosis of mucopolysaccharidoses. Mol Genet Metab. 2013;110(1-2):42-53.

4. Zhou J, Lin J, Leung WT, Wang L. A basic understanding of mucopolysaccharidosis: Incidence, clinical features, diagnosis, and management. Intractable Rare Dis Res. 2020;9(1):1-9. 
5. McBride KL, Flanigan KM. Update in the Mucopolysaccharidoses. Semin Pediatr Neurol. 2021;37:100874.

6. Hobbs JR, Hugh-Jones K, Barrett AJ, Byrom N, Chambers D, Henry K, et al. Reversal of clinical features of Hurler's disease and biochemical improvement after treatment by bone-marrow transplantation. Lancet. 1981;2(8249):709-12.

7. Lampe C, McNelly B, Gevorkian AK, Hendriksz CJ, Lobzhanidze TV, Pérez-López J, et al. Transition of patients with mucopolysaccharidosis from paediatric to adult care. Mol Genet Metab Rep. 2019;21:100508.

8. Kresse H, von Figura K, Klein U, Glössl J, Paschke E, Pohlmann R. Enzymic diagnosis of the genetic mucopolysaccharide storage disorders. Methods Enzymol. 1982;83:559-72.

9. Tomatsu S, Montaño AM, Oikawa H, Smith M, Barrera L, Chinen Y, et al. Mucopolysaccharidosis type IVA (Morquio A disease): clinical review and current treatment. Curr Pharm Biotechnol. 2011;12(6):931-45.

10. Morrone A, Caciotti A, Atwood R, Davidson K, Du C, Francis-Lyon P, et al. Morquio A syndromeassociated mutations: a review of alterations in the GALNS gene and a new locus-specific database. Hum Mutat. 2014;35(11):1271-9.

11. Hendriksz CJ, Berger KI, Giugliani R, Harmatz P, Kampmann C, Mackenzie WG, et al. International guidelines for the management and treatment of Morquio A syndrome. Am J Med Genet A. 2015;167A(1):11-25.

12. Montano AM, Tomatsu S, Gottesman GS, Smith M, Orii T. International Morquio A Registry: clinical manifestation and natural course of Morquio A disease. J.Inherit.Metab Dis. 2007;30(2): 165-174.

13. Harmatz P, Mengel KE, Giugliani R, Valayannopoulos V, Lin SP, Parini R, et al. The Morquio A clinical assessment program: baseline results illustrating progressive, multisystemic clinical impairments in Morquio A subjects. Mol Genet Metab. 2013;109:54-61.

14. Lavery C, Hendriksz C. Mortality in patients with Morquio syndrome A. JIMD Rep. 2015;15:59-66.

15. Tomatsu S, Mackenzie WG, Theroux MC, Mason RW, Thacker MM, Shaffer TH, et al. Current and emerging treatments and surgical interventions for Morquio A syndrome: a review. Res Rep Endocr Disord. 2012;2012(2):65-77.

16. Sawamoto K, Álvarez González JV, Piechnik M, Otero FJ, Couce ML, Suzuki Y, Tomatsu S. Mucopolysaccharidosis IVA: Diagnosis, Treatment, and Management. Int J Mol Sci. 2020;21(4):1517.

17. Hendriksz CJ, Burton B, Fleming TR, Harmatz P, Hughes D, Jones SA, et al. Efficacy and safety of enzyme replacement therapy with BMN 110 (elosulfase alfa) for Morquio A syndrome (mucopolysaccharidosis IVA): a phase 3 randomised placebo-controlled study. J Inherit Metab Dis. 2014;37(6):979-990.

18. Hendriksz CJ. Elosulfase alfa (BMN 110) for the treatment of mucopolysaccharidosis IVA (Morquio A Syndrome). Expert Rev Clin Pharmacol. 2016;9(12):1521-1532.

19. Lyseng-Williamson KA. Elosulfase Alfa: a review of its use in patients with mucopolysaccharidosis type IVA (Morquio A syndrome). BioDrugs. 2014;28(5):465-75. 
20. Hendriksz CJ, Parini R, AlSayed MD, Raiman J, Giugliani R, Solano Villarreal ML, et al. Long-term endurance and safety of elosulfase alfa enzyme replacement therapy in patients with Morquio $A$ syndrome. Mol Genet Metab. 2016;119(1-2):131-143.

21. Cleary M, Davison J, Gould R, Geberhiwot T, Hughes D, Mercer J, et al. Impact of long-term elosulfase alfa treatment on clinical and patient-reported outcomes in patients with mucopolysaccharidosis type IVA: results from a Managed Access Agreement in England. Orphanet J Rare Dis. 2021;16(1):38.

22. Hughes D, Giugliani R, Guffon N, Jones SA, Mengel KE, Parini R, et al. Clinical outcomes in a subpopulation of adults with Morquio a syndrome: results from a long-term extension study of elosulfase alfa. Orphanet J Rare Dis. 2017;12:98.

23. Akyol MU, Alden TD, Amartino H, Ashworth J, Belani K, Berger Kl, et al. Recommendations for the management of MPS IVA: systematic evidence- and consensus-based guidance. Orphanet J Rare Dis. 2019;14(1):137.

24. Muenzer J. Early initiation of enzyme replacement therapy for the mucopolysaccharidoses. Mol Genet Metab. 2014;111(2):63-72.

25. Concolino D, Deodato F, Parini R. Enzyme replacement therapy: efficacy and limitations. Ital J Pediatr. 2018;44 Suppl 2:120.

26. Barton NW, Brady RO, Dambrosia JM, Di Bisceglie AM, Doppelt SH, Hill SC, et al. Replacement Therapy for Inherited Enzyme Deficiency-Macrophage-Targeted Glucocerebrosidase for Gaucher's Disease. N Eng J Med. 1991;324:1464-1470.

27. Aldurazyme®, European public assessment report. https://www.ema.europa.eu/en/medicines/human/EPAR/aldurazyme. Accessed 1 Oct 2021.

28. Naglazyme®. European public assessment report. https://www.ema.europa.eu/en/medicines/human/EPAR/naglazyme. Accessed 1 Oct 2021.

29. Elaprase ${ }^{\circledR}$, European public assessment report. https://www.ema.europa.eu/en/medicines/human/EPAR/elaprase. Accessed 1 Oct 2021.

30. MEPSEVII®, European public assessment report. https://www.ema.europa.eu/en/medicines/human/EPAR/mepsevii. Accessed 1 Oct 2021.

31. Parini R, Deodato F. Intravenous Enzyme Replacement Therapy in Mucopolysaccharidoses: Clinical Effectiveness and Limitations. Int J Mol Sci. 2020;21(8):2975.

32. Heard JM, Vrinten C, Schlander M, Bellettato CM, van Lingen C, Scarpa M; MetabERN collaboration group. Availability, accessibility and delivery to patients of the 28 orphan medicines approved by the European Medicine Agency for hereditary metabolic diseases in the MetabERN network. Orphanet $J$ Rare Dis. 2020;15(1):3.

33. Stepien KM, Kieć-Wilk B, Lampe C, Tangeraas T, Cefalo G, Belmatoug N, et al. Challenges in Transition From Childhood to Adulthood Care in Rare Metabolic Diseases: Results From the First Multi-Center European Survey. Front Med (Lausanne). 2021;8:652358.

34. Puckett Y, Mallorga-Hernández A, Montaño AM. Epidemiology of mucopolysaccharidoses (MPS) in United States: challenges and opportunities. Orphanet J Rare Dis. 2021;16(1):241. 
35. Malm G, Lund AM, Månsson JE, Heiberg A. Mucopolysaccharidoses in the Scandinavian countries: incidence and prevalence. Acta Paediatr. 2008;97(11):1577-81.

36. Luzzatto L, Hyry HI, Schieppati A, Costa E, Simoens S, Schaefer F, et al. Outrageous prices of orphan drugs: a call for collaboration. Lancet. 2018;392(10149):791-794.

37. Mitchell J, Berger KI, Borgo A, Braunlin EA, Burton BK, Ghotme KA, et al. Unique medical issues in adult patients with mucopolysaccharidoses. Eur J Intern Med. 2016;34:2-10.

38. Parini R, Biondi A. The new frame for Mucopolysaccharidoses. Ital J Pediatr. 2018;44 Suppl 2:117.

39. Stepien KM, Gevorkyan AK, Hendriksz CJ, Lobzhanidze TV, Pérez-López J, Tol G, et al. Critical clinical situations in adult patients with Mucopolysaccharidoses (MPS). Orphanet J Rare Dis. 2020;15(1):114.

\section{Figures}




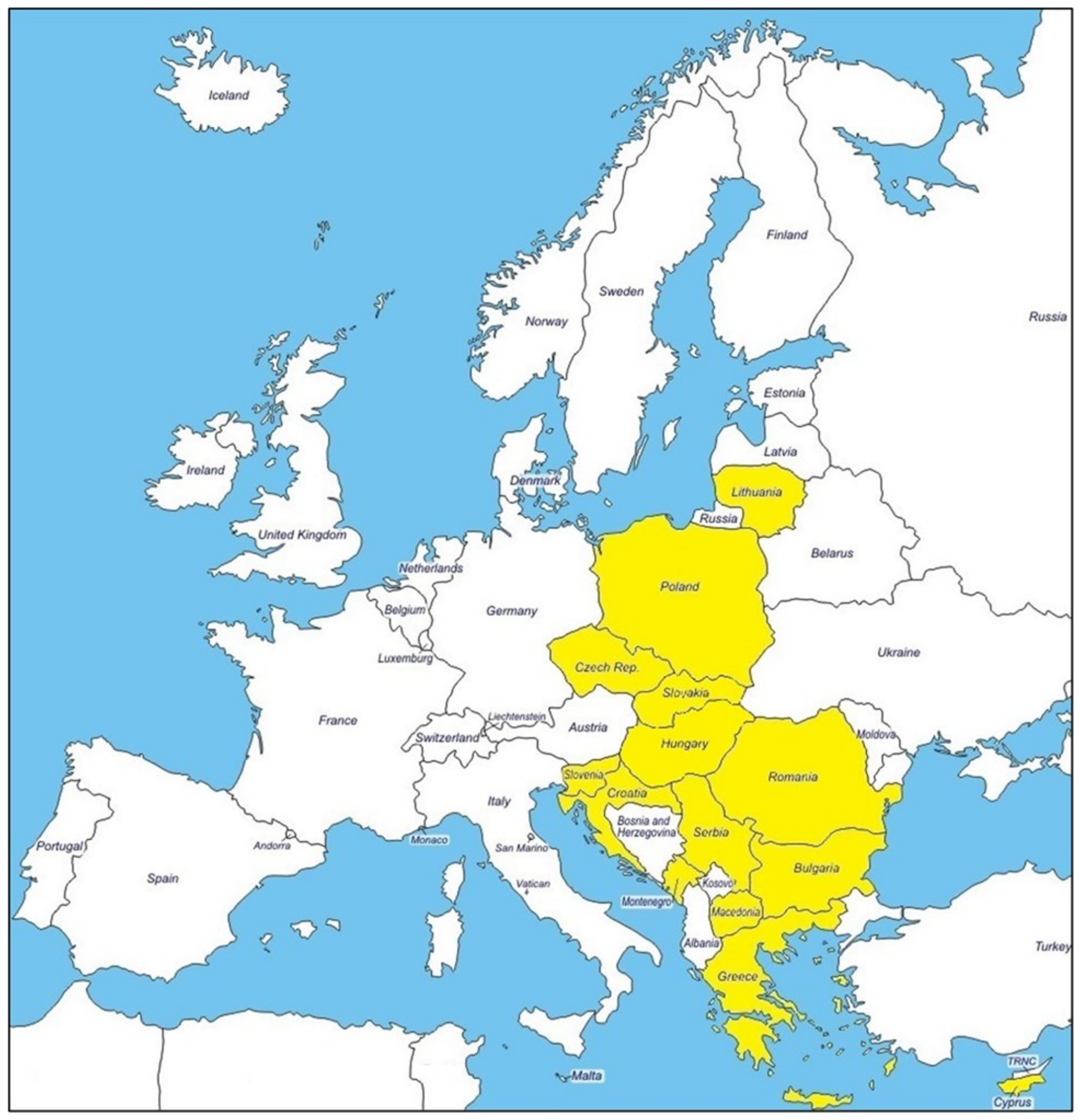

Figure 1

South and Eastern European countries involved in the "Mucopolysaccharidosis Management Physician Survey", in yellow. 


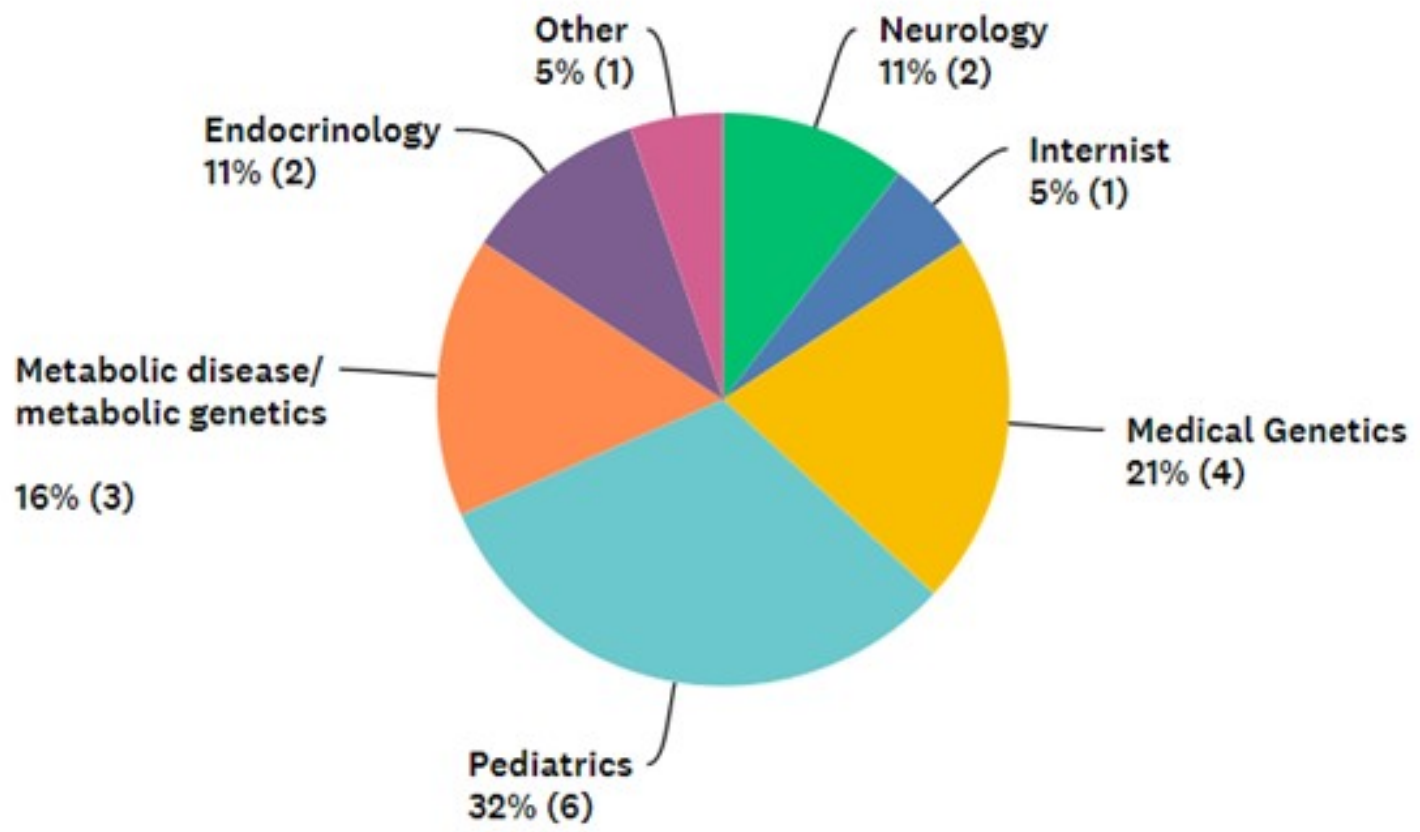

Figure 2

Physicians' main specialty as reported after the first survey. 


\section{MPS TYPES (\%) IN THE CENTERS}

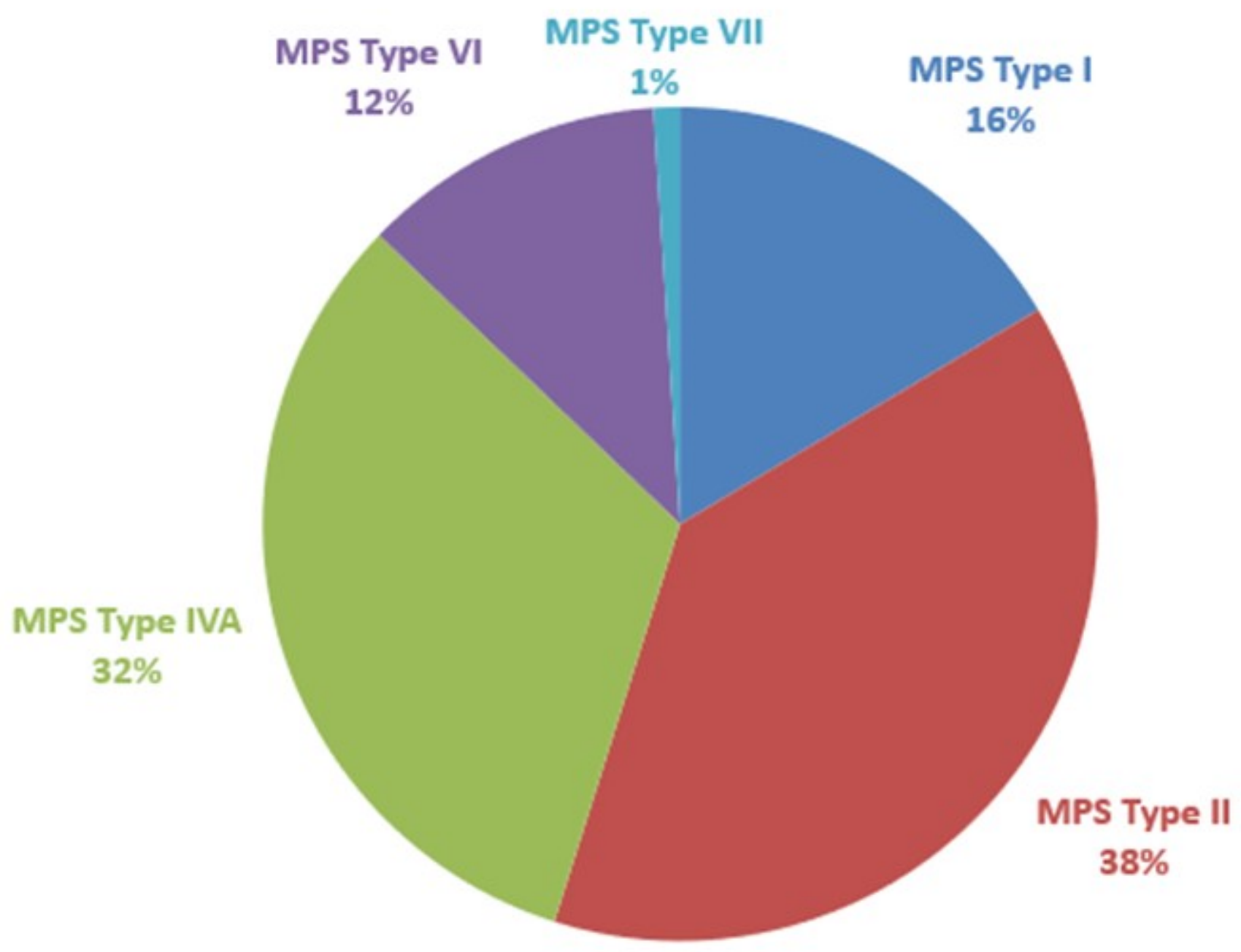

Figure 3

Relative frequency (\%) of MPS types in the population of patients from all centers. 


\section{PREVALENCE OF MPS TYPES IN TREATED PATIENTS}

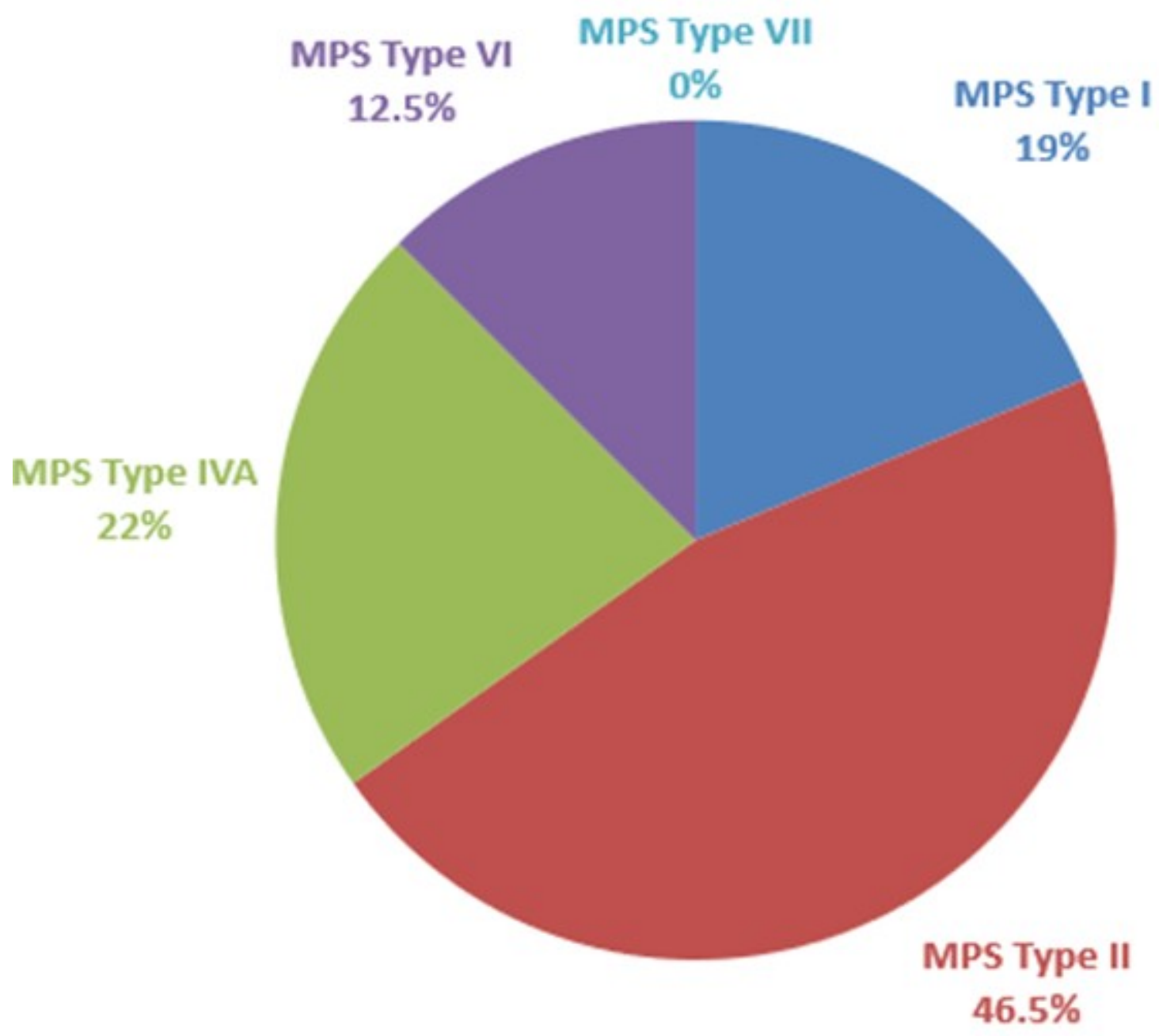

Figure 4

Relative frequency (\%) of MPS types in the population of ERT treated patients. 


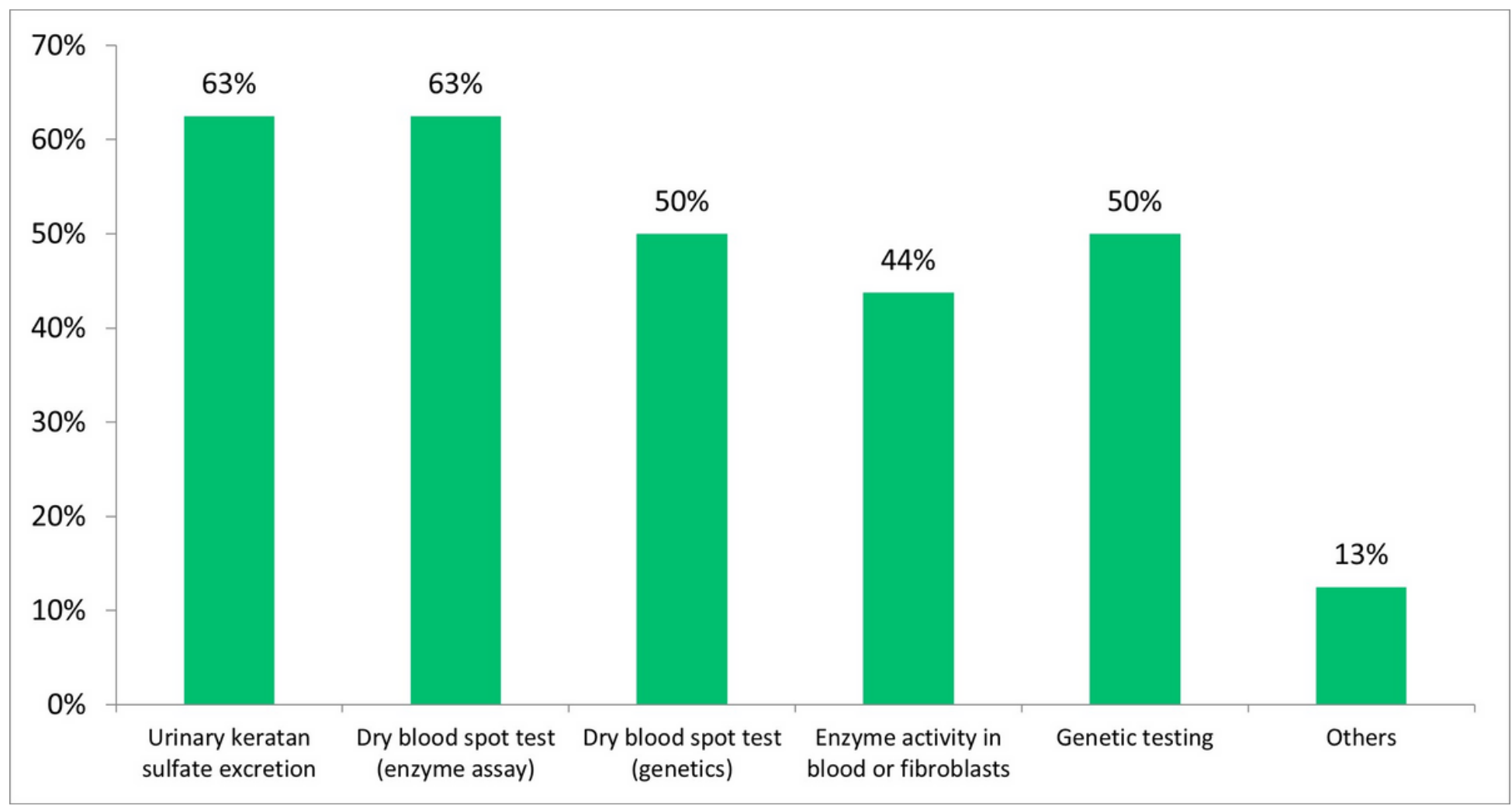

\section{Figure 5}

Appropriate methods to confirm diagnosis of MPS IVA before starting ERT treatment (\% of respondents).

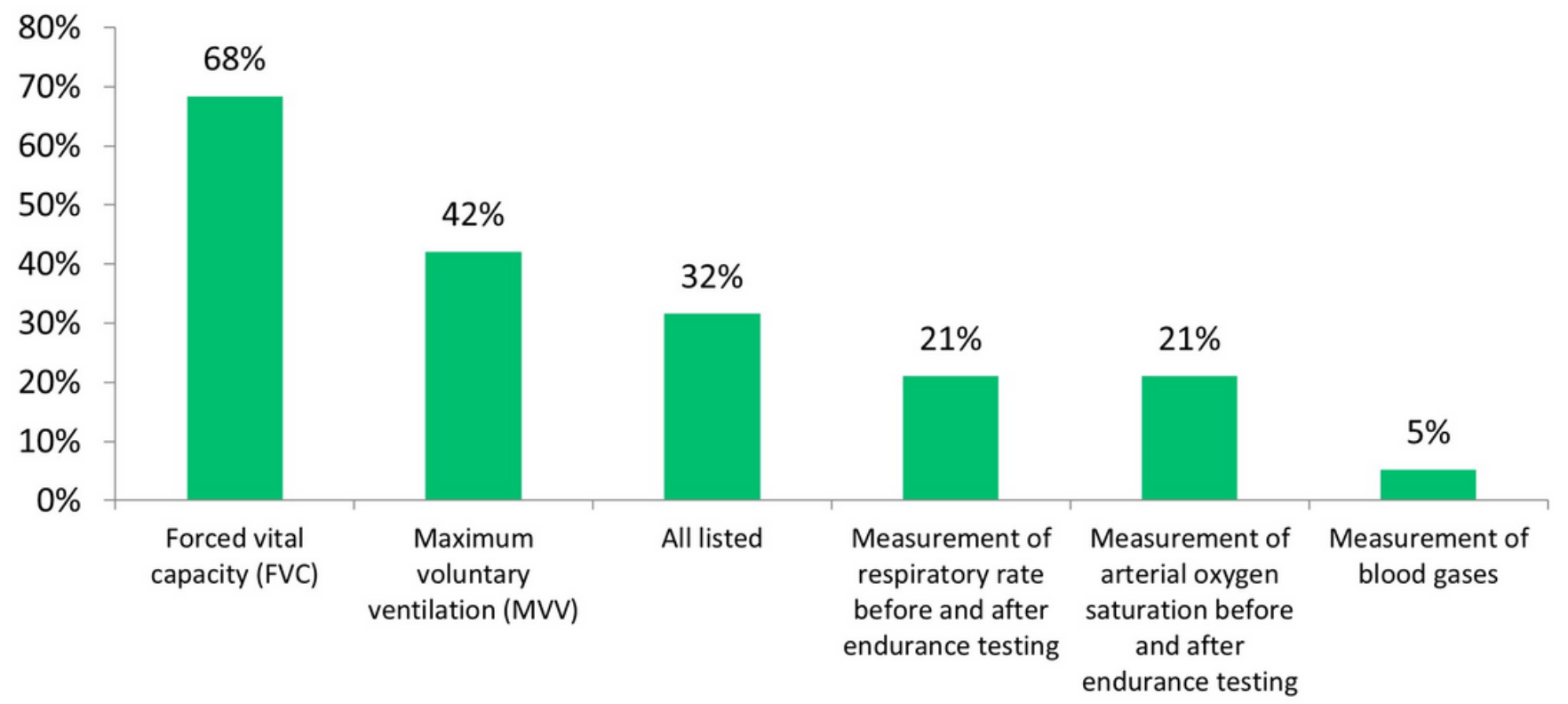

Figure 6 
Respiratory function parameters considered appropriate to demonstrate the clinical benefit of ERT in patients with MPS IVA (\% of respondents).

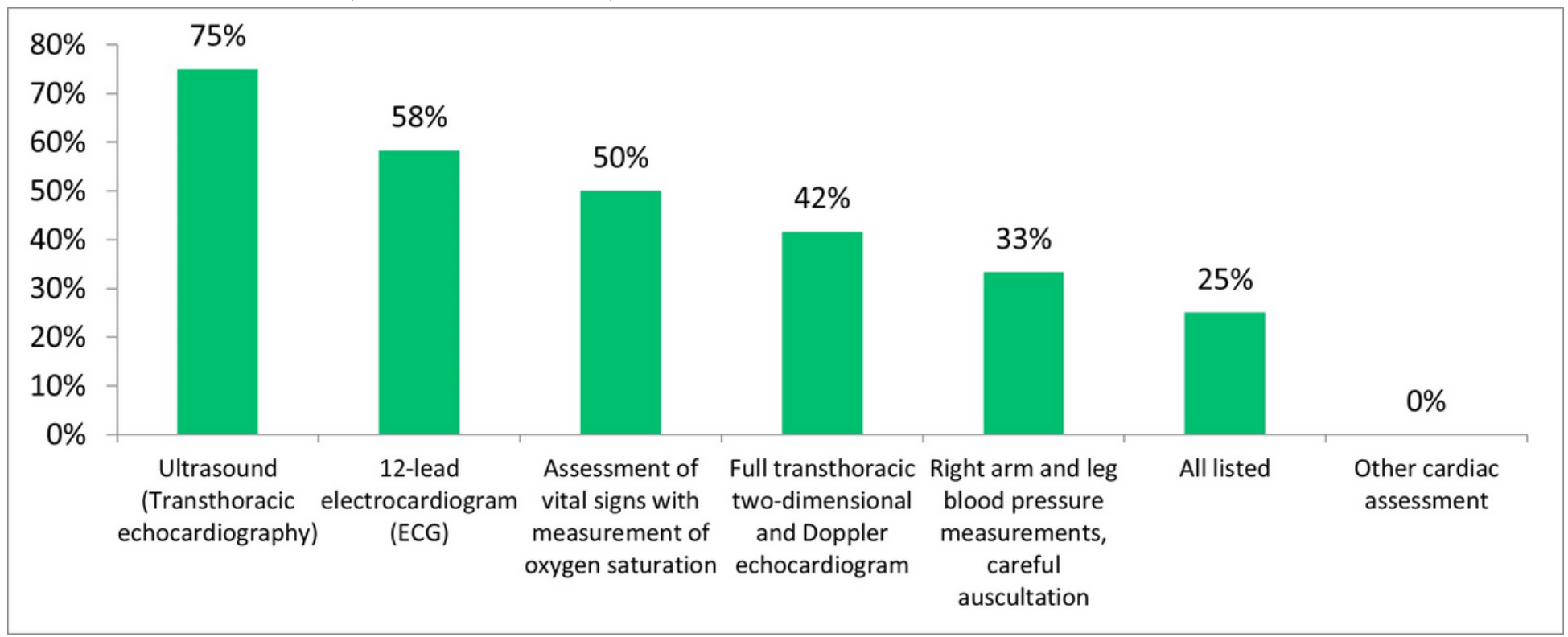

\section{Figure 7}

Cardiac function parameters considered appropriate to demonstrate the clinical benefit of ERT in patients with MPS IVA (\% of respondents). 